Michael Nagler ${ }^{1,2}$; Tamam Bakchoul ${ }^{3,4}$

5

6 Affiliations:

$7{ }^{1}$ Department of Haematology, Inselspital, Bern University Hospital, CH-3010 Bern, Switzerland

8

\section{Clinical and lLaboratory tests for the diagnosis of heparin-induced thrombocytopenia}

${ }^{2}$ Department of Clinical Research, University of Bern, CH-3010 Bern, Switzerland

${ }^{3}$ Center for Clinical Transfusion Medicine, University Hospital of Tübingen, 72076 Tübingen,

Germany

${ }^{4}$ Insitute for Immunology and Transfusionsmedizin, Universitätsmedizin Greifswald, Germany

Correspondence: $\quad$ Tamam.Bakchoul@med.uni-tuebingen.de; Center for Clinical Transfusion Medicine, University Hospital of Tübingen, 72076 Tübingen, Germany; phone +497071 2981601; fax +497071295240

Running head: $\quad$ Laboratory tests for HIT

Text word count:

Abstract word count: $\quad 145 \underline{250}$

Figures: $\quad 2 \underline{3}$

Tables: 3

References: $\quad 100$

Review article 


\section{Summary}

2 A rapid diagnostic work-up is required in patients with suspected heparin-induced

3 thrombocytopenia (HIT). However, diagnosis of HIT is challenging due to a number of practical

4 issues and methodological limitations. Many laboratory tests and a few clinical scoring systems

5 are available but the individual characteristics and the diagnostic accuracy of these are hard to

6 appraise. The 4Ts score is a well evaluated clinical assessment tool with the potential to rule-out

HIT in many patients. Still, it requires Scoring tools such as the 4Ts are time-consuming, require experience and are-is subject to a relevantn inter-observer variability. Immunoassays such as enzyme-linked immunosorbent assays or recently developed rapid assays are able to exclude HIT in a number of patients. But, a Accuracy of immunoassays differs depending on type of assay, threshold, antibody specificity and even manufacturer. Due to a comparatively low positive predictive value, HIT cannot be confirmed with by immunoassays alone. In addition, only some of them are immediately accessible, particularly in small laboratories.-While functional assays such as the serotonin release assay (SRA) and the heparin-induced platelet activation assay (HIPA) are considered a gold standard for diagnosis of HIT, they require a highly specialised laboratory. In addition, and manysome of them are not adequately evaluated. In clinical practice, we recommend an integrated diagnostic approach combining not only clinical assessment (the

4Ts score) but immunoassays and functional assays as well. We propose a clear diagnostic algorithm supporting clinical decision-making. Furthermore, In this review, we provide an overview of all current laboratory techniques for HIT and discuss diagnostic pathways and strategies to reduce diagnostic errors, and future perspectives.

Keywords: Heparin/adverse effects; Immunoassay/methods; Thrombocytopenia/chemically induced; Thrombocytopenia/diagnosis 


\section{Introduction}

3 Diagnostic work-up of patients with suspected heparin-induced thrombocytopenia (HIT) is hampered by major practical issues and a number of methodological limitations. OftenNot infrequently, suspicion is raised during night shifts and-weekends when haematology consultants and elaborated laboratory services are not available. Thus, surgical registrars or intensive care unit consultants who are inexperienced with such patients may face major clinical decisions at times when there is little support. Most accurate diagnostic tests are functional assays, which are time-consuming, expensive and require a high level of laboratory expertise (1-3). Even in the best case scenario, results of these gold-standard tests will take at least two days and will only be available from Monday to Friday (4-6). However, the clinical decision regarding whether or not heparin should be stopped and treatment with an alternative anticoagulant started, must be made immediately within a few hours (7-10). Delaying this decision- may be life-threatening in patients with HIT (11), while treatment with alternative anticoagulants in non-HIT patients can be associated with major risks (12-14). Some clinical scoring systems and a number of immunoassays (Table 1) are currently available to help physicians select the most appropriate course of action. However, the diagnostic accuracy varies across these tests and all are associated with limitations (15). Given the large number of publications describing heterogeneous study designs and reporting imprecise and varying results,, it is hard to appraise the diagnostic characteristics of individual tests.

With a focus on laboratery assays, wIn the present article, we will review the currently available diagnestic clinical and laboratory tests, summarise their diagnostic accuracy data and discuss practical issues. We will also elaborate on test variations and discuss strategies to reduce overdiagnosis.

\section{Diagnostic pathways}

While estimating the value of diagnostic tests, it is helpful to appreciate the pathways in which they are used. Thus, we describe typical scenarios requiring a diagnosis of HIT that physicians may find themselves in, which will generally be informed by previous training and the technical infrastructure of the hospital. In virtually all situations, physicians must make an initial clinical 
decision while awaitingwaiting for the results of the functional assay and the following scenarios may arise. First, the associated laboratory does not provide access to a rapid assay, no immediate access to a laboratery tests is available, neither a functional assay nor an immuneimmuno-assay, because (e.g. enzyme-linked immunosorbent assay [ELISA] is conducted, which is ustally earried outonce or twice a week only). In this setting, thea initial decision is solely made on the basis of the estimated clinical probability using one of the validated scoring tools. The accuracy of the decision critically depends on the characteristics and appropriate execution of the clinical test. The decision may be revised when the immunoassay test result arrives several days later.

However, most authors and recent guidelines recommend against conducting an immunoassay in patients with a low risk score $(9,16,17)$. In the second scenario, an immunoassay is available Monday to Friday and a functional assay once a week. As above, physicians must decide on the outcome of the clinical tool but decisions can be revised quickly. This strategy puts equal weight on the clinical scoring system as well as laboratory test results. In the third case, an immunoassay is conducted via a 24-hour service and the results of a functional assay will be reported at least once a week. In this preferable situation, physicians can consider clinical characteristics as well as results of immunoassays, and decisions will be modified accordingly eorrected-within a few days. However, in this scenario-physicians may be tempted(tend?) to skip replace the fairly time-consuming task of gathering all information for clinical risk assessment with a laboratory test only (e.g. a rapid immunoassay), what places the patients at particular risks. filling a clinical assessment form and instead rely exclusively on the results from an immunoassay, which also have specific limitations. In all the above-mentioned scenarios, patient care can relevantly be improved with the help of the local haematology/couagulation consultancy service. As experienced in clinical, haematology consultation-which may reducees the number of false-classified 4Ts scorings and improves interpretation of laboratory results. In addition, prophylactic treatment with fondaparinux can often be implemented in unclear cases Furthermore, it may save costs by reducing unnecessary testing and treatment with alternative anticoagulants.

it is also possible to request and assessment of clinical probability and interpretation of taboratory results from the local haematology consultancy service. In clinical practice, many inappropriate decisions can be corrected this way, but it is a time-consuming and perhapsexpensive intervention. 
Assessing the pretest probability: clinical scoring tools

As illustrated above, standardised assessment of the clinical probability of HIT is an essential step in the work-up of patients with suspected HIT. If conducted correctly, the probability of HIT can be estimated before determination of a laboratory test. Several clinical assessment tools have been developed, the outputs of which not only affect the interpretation of any laboratory test result but may in some instances represent the only diagnostic test to guide therapeutic decisions

(see Figure 2 1).

\section{The 4Ts score}

The most extensively studied assessment tool, the 4Ts score, incorporates four typical clinical features of HIT: (i) thrombocytopenia, (ii) characteristic timing of thrombocytopenia, (iii) presence of thrombosis or other clinical sequelae, and (iv) the absence of other causes of thrombocytopenia, $(-(8)$, Table 1$)$. The pretest probability is estimated to be low (0 to 3 points), intermediate ( 4 or 5 points), or high with 6 to 8 points $(18,19)$. A number of evaluation studies assessed the diagnostic accuracy of the 4Ts score $(18,20-30)$ and a meta-analysis suggested a high negative predictive value (99.8\%; 95\% CI: 97-100\%) (19). This result was not influenced by the type of performer (laboratory or treating physician), the prevalence, or the clinical setting as studied in sensitivity analyses. According to_this meta-analysisstudy, the probability of suffering from HIT can be estimated to be $0.82 \%$ in low risk 4Ts scoring, $13.414 \%$ (95\% CI: 9 to $\underline{22 \%)}$ in intermediate scoring and $50.636 \%(95 \%$ CI: 40 to $82 \%)$ in the high risk scoring. However, theThese results are clearly unsatisfactory for the purpose of ruling-inconfirming HIT. positive predictive value of an intermediate or even high 4Ts score was found to beunsatisfactory (14\%; 95\% CI: $9-22 \%$ and $64 \% ; 95 \% \mathrm{CI}: 40-82 \%$, respectively). While the use of the 4Ts score as a screening test in the diagnostic pathways has been suggested, some methodological issues have been raised, in particular with regard to determination in clinical practice $(31,32)$. Most importantly, application of diagnostic accuracy measures to clinical practice was questioned because assessment of the 4Ts score was done by experts instead of referring physicians in most of the diagnostic accuracy studies (31). Indeed, a very recent, welldesigned prospective study considering these issues reported a much more limited diagnestic aceuracysensitivity of the 4Ts score than estimated in the above mentioned meta-analysis (sensitivity $81.3 \%$; $95 \%$ CI: 67.7, 94.8; specificity 63.8\%; 95\% CI: 59.6-68.0\%) and a limited 
agreement between physicians and expert observers (Cohens kappa 0.43; 95\% CI, 0.29-0.57)

(33). In clinical practice, we experienced several misdiagnosedses sed-HIT cases due to low risk 4Ts scorings and Figure 2 illustrates the dreadful course of a 30-year-old female patient who xxxxdied in the course of cerebral vein thrombosis. Thus, some authors conclude that a negative $(\leqslant \leq 3) 4 \mathrm{~T}$ 's score alone is insufficient to exclude HIT in clinical practice $(24,34)$.

\section{The HEP score}

The HIT expert probability (HEP) score is another clinical assessment tool which incorporates more clinical features than the 4Ts score (magnitude of platelet count fall, timing of platelet count fall, nadir platelet count, thrombosis, skin necrosis, acute systemic reaction, bleeding and other causes of thrombocytopenia) (29). Each of these features is evaluated using a score ranging from -3 (inconsistent with a HIT diagnosis) to +3 (consistent with a HIT diagnosis). Application of the HEP score resulted in a higher inter-observer agreement than the 4Ts score in one evaluation study (29). A cut-off value of 5 was associated with a positive predictive value of $55 \%$ and a negative predictive value of $97 \%$, showing operating characteristics similar to those observed with the 4Ts score. Nevertheless, the HEP score is more complex and may be more time consuming than the 4Ts. In addition, the number of evaluation studies is much more limited.

\section{Other scoring systems}

Another, simple score to exclude HIT has been suggested by Messmore et al (35). The system is designed to arrive at low (0) or possible (1) probability scores depending on the presence or absence of typical HIT manifestations without knowledge of laboratory test results (except platelet counts). In one evaluation study, it was able to exclude patients without HIT efficiently and it might be more useful for physicians who are not HIT experts. Lillo-Le Louët and colleagues developed a score to assess the probability of HIT in patients following cardiopulmonary bypass surgery (20). This score incorporates 3 variables that were predictive for HIT in a retrospective study (a biphasic platelet count profile, an interval of $>5$ days from $\mathrm{CPB}$ to the first day of suspected HIT and a CPB duration of $>118$ minutes). In an independent study, this score demonstrated a negative predictive value of $78 \%$, suggesting that it may have inadequate sensitivity to be used as a clinical screening test (36). However, both the Mesmore
Feldfunktion geändert

Formatiert: Schriftart: $12 \mathrm{Pt}$. Formatiert: Schriftart: $12 \mathrm{Pt}$. Feldfunktion geändert 
1 and Lillo-Le Louët scores require more validation in larger prospective studies before firm

2 conclusions regarding their diagnostic accuracy can be drawn.

\section{Immunoassays}

Acquired thrombocytopenia is a frequent finding in hospitalised patients treated with heparin. Often, HIT is difficult to exclude or to confirm based on clinical information alone and physicians rely heavily on laboratory tests. Two classes of assays are available: functional (platelet activation) assays and (PF4-dependent) immunoassays. Immunoassays are pivotal in the diagnostic work-up of patients with suspected HIT and rely on detection of antibody binding by ELISA or particle-based immunoassays. However, diagnostic accuracy of immunoassays is quite variable. As an example, Figure $1 \underline{3}$ illustrates the difference of the probability of having HIT after a positive (or negative test respectively) between two available assays.

\section{Enzyme-linked immunosorbent assays (ELISAs)}

In ELISA, the target antigen (PF4/polyanion complexes) is bound to the solid phase, e.g. microtitre plate wells. Patient serum or plasma is added and an enzyme-labeled secondary antibody is used to detect the amount of anti-PF4/heparin antibodies bound in a semi-quantitative fashion. The intensity of the colour change, measured as optical density (OD), is proportional to the concentration of bound antibodies. The first polyspecific ELISA was developed by Amiral and Greinacher in 1992 (37, 38). Sensitivity was comparable to a heparin-induced platelet activation assay (HIPA) as evaluated in 209 patients with a clinical diagnosis of HIT (38). Since then, several in-house and commercially available assays have been developed and many studies have evaluated their performance characteristics (Table 1) (20, 21, 23, 24, 26-28, 39-63). A recent meta-analysis pooled this data and calculated the diagnostic accuracy according to different cut-off values: low threshold $(\mathrm{OD} \leq 0.7$, according to or slightly above the manufacturer's instructions), intermediate threshold (OD 0.8 to 1.4) and high threshold (OD > 1.4). Sensitivity of the polyspecific ELISA was excellent at low threshold (see Table 2) (64)_(63) but relevant differences were observed with regard to different thresholds and particular manufacturers. However, specificity was limited for all assays (Table 2), restricting their value as a confirmatory test. With regard to ELISA, a significant inter-laboratory variation was observed 
1

in a North American proficiency testing programme, in particular with regard to weak positive results (65).

Following in vitro observations on the specificity of platelet-activating PF4/H-antibodies, IgGspecific ELISAs were developed and tested in a number of studies $(23,41,43,45,46,48,56,66-$ 72). At low thresholds, sensitivity is again excellent (Table 2). However, even though several studies suggested a higher specificity than polyspecific assays (23), this observation was not generalizable in the above-mentioned meta-analysis (73). Data pooled from all available evaluation studies revealed a specificity of $85.4 \%$ for IgG-specific ELISAs (95\% CI: 78.290.6\%), and $86.8 \%$ for polyspecific ELISAs (95\% CI: 82.0-90.5\%). While these ELISA assays can be excellent screening tests, they do have the major drawbacks of being time consuming and requiring a specialised laboratory.

\section{Particle-based immunoassays}

Several types of tests have been developed to overcome the drawbacks of ELISA assays: particle gel immunoassays (PaGIA), lateral flow immunoassays, chemiluminescent immunoassays [CLIA] and latex agglutination assays. PaGIA as well as lateral flow immunoassay can be implemented in routine laboratories, conducted 24-hours a day and technicians can perform these without specialised training. The polyspecific PaGIA is a particle agglutination assay uses the gel technique of ID-Micro typing with polymer particles coated with PF4/heparin complexes (52). It has been evaluated in a number of studies $(21-24,26,33,44,45,52,54,55,71,72,74,75)$. The sensitivity as well as the specificity of the PaGIA was excellent; the specificity was even higher than ELISA assays with low threshold (cutt-off according to manufacturer's instructions; Table 2, (73)). The principle of the lateral-flow immunoassay, which is a different particle-based immunoassay, is well known from modern pregnancy tests: labeled antibody complexes are retained and become visible during capillary action (71). The diagnostic characteristics have been evaluated in several studies $(59,69-72,75,76)$ from which the data have been pooled and a high sensitivity and reasonable specificity have been confirmed (Table 2; (73)). Nevertheless, PaGIA and lateral flow immunoassays share two disadvantages. First, the results are assessed visually (even though automatic applications exist), which permits variation in interpretation. Second, the results are expressed positively or negatively and titration studies are necessary to determine the anti-PF4/H antibody concentration (24). In addition, PaGHA is only available as a 
polyspecific test. The particle immunofiltration assay is a different assay, but as yet has not been shown to demonstrate adequate diagnostic accuracy $(73,77)$.

A desirable characteristic of tests to be implemented in modern laboratories is that they can be automated allowing them to be run 24 hours a day. Two assays have been developed to meet this demand: the chemiluminescent immunoassay-CLIA (polyspecific HemosIL ${ }^{\circ}$ AcuStar HIT$\mathrm{Ab}$ and IgG-specific HemosIL ${ }^{\circ}$ AcuStar HIT-IgG) and the latex agglutination assay (polyspecific HemosIL® HIT-Ab). Both assays can be used with the BIO-FLASH® analyzer (Inova Diagnostics, San Diego, CA, USA) or the ACL TOP coagulometers (Instrumentation Llaboratory, Bedford, MA, USA). Magnetic coated particles capture the PF4/heparin antibodies and in case of chemiluminescent immunoassayCLIA emitted light is measured (78). The diagnostic accuracy of these assays has been investigated in several large cohorts with favourable results $(56,58,78-81)$. At low threshold, sensitivity was very high for both the polyspecific and the IgG-specific tests (Table 2) (73). Furthermore, a combination of a high sensitivity with a high specificity was estimated for the polyspecific assay (intermediate threshold) as well as IgG-specific assay (low threshold). Coated latex beads are used instead of magnetic particles with the polyspecific latex agglutination assay. In one evaluation study, sensitivity was found to be excellent, specificity was moderate (80)(Table 2).

Diagnostic accuracy measures of rapid immunoassays have also been studied in another recent systematic review and meta-analysis comprising essentially the same primary studies cited above (82). A high sensitivity and specificity (corresponding to a high negative predictive value) was observed for some of the assays as well (PaGIA, lateral flow immunoassay and IgG-specific chemiluminescent immunoassayCLIA), suggesting their usefulness in diagnostic algorithms-as mentioned below. In addition, implementation of rapid immunoassays is also supported by a study which modeled evaluated?the cost impact (83).

\section{Functional assays}

A subset of PF4/heparin-antibodies is able to activate platelets and cause clinical HIT under certain conditions $(8,84)$. The presence of platelet-activating antibodies can only be established using functional assays. In all tests, patient plasma or serum is incubated with donor platelets which can be prepared in one of two different ways: either as (a) washed platelets, or as (b) 
1 platelet rich plasma (PRP) or whole blood (1). Washed platelet assays are considered preferable

2 over other PRP or whole blood tests, because remaining plasma/serum may influence the

3 antigen-antibody interaction as well as platelet activation $(2,8,9,85,86)$. Table 3 summarizes

4 the characteristics of the assays most often used.

$5 \quad$ Washed platelet assays

6 Both the serotonin release assay (SRA) and heparin induced platelet activation (HIPA) assay utilise washed platelets. Platelet activation is assessed by measurement of the release of ${ }^{14} \mathrm{C}$ labeled serotonin from test platelets in SRA and or by visually determining the formation of platelet aggregates in $\operatorname{HIPA}(87,88)$.

In the HIPA assay, washed platelets from four healthy unselected donors are incubated with patient serum in the presence of buffer or heparin $(0.2 \mathrm{IU} / \mathrm{mL}$ and $100 \mathrm{IU} / \mathrm{mL})$. Incubation takes place in a round-bottom microtitre plate, with spinning magnetic spheres as a source of shear force. Platelet aggregate formation is determined visually at 5-minute intervals; the test is positive if aggregation is observed within 30 minutes (at $0.2 \mathrm{IU} / \mathrm{mL}$ but not at $100 \mathrm{IU} / \mathrm{mL}$ heparin) using platelet suspensions from at least two of the four donors.

In the SRA, platelets obtained from a selected donor are pre-incubated with radioactive $14 \mathrm{C}$ serotonin. After washing, platelets are incubated with patient serum and heparin in flat-bottomed microtitre wells in duplicate on a plate shaker. After incubation for 60 minutes and centrifugation, supernatants of each reaction mixture are collected, and radioactivity is measured. Test results are expressed as percentage of serotonin release (compared to the $100 \%$ value obtained by detergent-induced platelet lysis). The test is considered positive if there is $>20 \%$ release at low heparin concentrations $(0.1$ to $0.3 \mathrm{IU} / \mathrm{mL})$ and $<20 \%$ release at supratherapeutic heparin levels $(100 \mathrm{IU} / \mathrm{mL})$. However, a number of laboratories use a threshold of $>50 \%$ serotonine release in order to increase specificity (89).

The SRA was initially validated using a set of samples from patients with different degrees of clinical probability of HIT and a very large set of controls obtained from patients with a broad spectrum of clinical characteristics $(87,90)$. Not only high sensitivity and specificity were observed, but also a clear trend between clinical probability of HIT and the SRA results. These findings were confirmed in a prospective study following up all patients with heparin treatment based on strict clinical criteria (86). Equivalent diagnostic characteristics have been observed in 
1 the evaluation of the HIPA test. Initially, Greinacher and co-workers studied sensitivity in 34

2 samples, followed by sera from 209 patients $(38,88)$. Both functional assays are considered the

3 "gold standard" for diagnosing HIT. However, these assays are difficult to perform, require

4 selected healthy platelet donors and are restricted to few reference laboratories. Moreover, the

5 SRA requires the use of the radioisotope, 14C-serotonin, which most laboratories try to avoid

6 due to regulatory and safety issues.

7 Even though SRA and HIPA are considered as gold standard for the diagnosis of HIT, some

8 cases with incongruous results were observed, eg. positive tests in combination with negative

9 immunoassays and an atypical clinical presentation (91). These rare cases were generally

10 considered to be "false-positive" (91). In clinical practice, it is important not to always use any

11 laboratory assay functional assays as the only test applied but to consider tin combination with

12 appropriate assessment of the clinical presentations and immunoassay test results as well.

Other washed platelet assays that either use ATP release detected by lumiaggregometry, plateletderived microparticle generation measured by flow cytometry, or proteolysis of Fc $\gamma$ RIIa (the receptor through which HIT immune complexes activate platelets) assessed by chemiluminescence have been described, but still require independent validation.

Whole blood assays

Platelet-activating antibodies can be detected using the whole blood impedance analyser (Multiplate ${ }$, multiple electrode platelet aggregometry) in the presence of heparin. Blood from a selected donor is collected in hirudin-containing tubes. UFH is then added $(0.5$ or $100 \mathrm{IU} / \mathrm{mL})$ and the suspension are incubated with patient citrated platelet-poor plasma (PPP) or heatinactivated serum. Changes in impedance are then recorded over a 15 minute period (92). In a multicentre Australian study, this assay, which does not require platelet preparation, demonstrated a sensitivity and specificity of $90.3 \%$ and $89.0 \%$, respectively $(81,92)$.

\section{Other functional assays}

A number of other, less elaborate functional assays have been suggested; of these the heparininduced platelet aggregation test (PAT) and flow cytometry are the most often used. In PAT, platelet aggregometry is performed in the presence of two heparin concentrations using PRP of one to four, selected or unselected donors $(85,93)$. However, evaluation studies have revealed 
1 varying results, partly explained by the modifications and selection of donors $(38,90,93,94)$. In general, sensitivity was clearly inferior to SRA/HIPA.

Flow cytometry assays have been developed by a number of authors. Serum of patients and platelets from unselected donors are incubated with heparin and different measures of platelet activation are recorded (Annexin V (44, 95, 96), P-selectin (44, 95), and microparticles (97, 98)). Although these assays showed some agreement with the gold standard, standardisation and further evaluation studies are needed.

\section{Strategies to improve the specificity of immunoassays}

Several strategies have been developed and introduced to improve the specificity of immunoassays, increase their positive predictive value and limit the number of patients over treated.

\section{Determination of PF4/Heparin antibody titres}

A number of studies have observed that higher optical density values (in the case of ELISA type assays) are associated with an increased probability of having HIT $(43,99)$. Higher titres of antibodies have also been correlated with the likelihood of HIT in the case of PaGIA (24) and chemiluminescent immunoassayCLIA $(58,81)$. To confirm these observations, we pooled the data of all available evaluation studies in a recently conducted meta-analysis (64). The cutt-off values used in the primary studies were categorised into low, intermediate and high thresholds (corresponding to a low, intermediate, and high antibody titres). In line with previous observations, we found a remarkably increased specificity (or positive likelihood ratio) in all immunoassays (poly- and IgG-specific ELISA, PaGIA, poly- and IgG-specific chemiluminescent immunoassayCLIA) (73). However, the negative likelihood ratio increased as well, corresponding to a decline in sensitivity. In Table 2, we report a summary of the results that might help to define the best threshold.

Application of IgG-specific assays

In-vitro data suggest that IgG-specific antibodies account for the vast majority of HIT cases and several studies indeed observed an increased specificity of IgG-specific assays compared to polyspecific tests while sensitivity also remained high $(23,86,100)$. We tried to confirm this 
observation by pooling all available data in the above-mentioned meta-analysis. However, this could be replicated only in part (Table 2) (73). In addition, sensitivity was somewhat reduced, at least with intermediate and high cutt-off values. In clinical practice, we recommend selecting an appropriate combination of antibody specificity and threshold according to the respective likelihood ratios (eg. polypecific ELISA/ chemiluminescent immunoassay ELIA/ PaGIA with intermediate threshold or IgG-specific ELISA/ chemiluminescent immunoassayELIA with a low threshold).

\section{Implementation of a high-dose heparin confirmation step}

It has been suggested that the specificity of HIT immunoassays could be improved by the implementation of a confirmatory step using supratherapeutic concentrations of heparin. This is because a persistently positive test despite high heparin concentrations can indicate an antibody that reacts against PF4, but not to the PF4/heparin complex. Such antibodies usually do not indicate HIT. While some studies support the use of this step, especially for weakly positive OD values $<1.0$ units, some of the clinically most relevant high-titre antibodies with strong plateletactivating capacity are not inhibited (101). A recent meta-analysis however did not find this strategy helpful (64). Sensitivity was found to be low, at least in a subgroup of samples with a high titre of antibodies $(73,85)$. Because of this limitation and the corresponding difficulties in interpretation, we recommend against implementing this in routine clinical practice.

\section{Current challenges and future perspectives}

While the incidence of HIT in uncomplicated patients can be anticipated to decline due to the increasing use of low molecular weight heparins and alternative, non-heparin anticoagulants (102), HIT will remain a particular issue in specific patient populations, which have undergone cardiac surgery or are severely ill patients. Despite the progress in understanding the pathophysiology of HIT, there are still numerous diagnostic issues and treatment challenges.

\section{The clinical dilemma}

The management of patients with suspected HIT is associated with two major risks: missing patients with HIT and overtreatment. Physicians rely heavily on immunoassay test results and immunoassays are an essential part of most diagnostic pathways as discussed above. However, as few as $10-15 \%$ of sera test positive for anti-PF4/heparin antibodies and only up to $50 \%$ of 
1 these contain clinically relevant, platelet-activating antibodies characteristic of HIT. Therefore, a considerable risk of "overdiagnosis" and subsequent mistreatment of patients without HIT exists

3 (14). These patients are exposed to relevant risks. Therapy with alternative anticoagulants is

4 associated with a high rate of bleeding complications (12), severe anaphylactic reactions (13),

5 higher costs, and requires more management generally than compared to heparin treatment (12,

6 14). Thus, an important aim of clinical practice and scientific inquiry is to develop and

7 implement diagnostic tests and algorithms that reduce the number of false-positive results.

8 On the other hand, increasing specificity should not be at the expense of test sensitivity, as

9 missing a diagnosis of HIT is dangerous (64). The risk of severe thromboembolic complications, limb loss and even death is high in untreated HIT patients $(11,103)$. There is increasing awareness that a low risk 4Ts score does not exclude HIT in all cases $(33,34)$ and Figure 2 illustrates a dreadful example. In addition, the sensitivity is below $95 \%$ in some immunoassays, suggesting that one in 20 HIT patients will be missed as well (64).-

\section{Diagnostic algorithms}

In order to avoid the above-mentioned risks, the most important challenge in clinical practice is to estimate the probability of an individual patient having HIT. Our considerations above suggest that neither an immunoassay, nor a clinical assessment score alone is able to correctly diagnose HIT. However, combining different diagnostic approaches (clinical and laboratory) can improve diagnostic accuracy and may represent a strategy to solve this clinical dilemma-(Figure 1). Diagnostic algorithms are the most obvious way of combining clinical and laboratory tests for the diagnosis of HIT $(24,33)$. In Figure $2 \underline{1}$, we illustrate a recently adapted diagnostic algorithm, (8). Assessing the clinical probability is suggested for all patients with suspected HIT. Given an appropriate application of the 4Ts score, HIT can be excluded in all-most patients with a low risk scoring. However, conducting the 4Ts score correctly is difficult (31) and determination of an immunoassay is suggested in all cases where there are uncertainties (eg. unclear heparin exposure, missing platelet numbers).-

In contrast, HIT should be considered if an applied 4Ts score is high. In all other cases, determination of a quantitative immunoassay is recommended. However, the diagnostic accuracy varies between different assays and we recommend selecting a test with a high sensitivity as well as a high specificity (64). For example, we recommend choosing an intermediate threshold (cut- 
1 off value) in the case of polyspecific ELISA, PaGIA, as well as polyspecific chemiluminescent

2 immunoassayCLIA. HIT can be essentially ruled-out if the immunoassay is negative or highly

3 suspected if high titres of antibodies are demonstrated (eg. OD>=3.0). Even though HIT must be

4 assumed in all other cases with a positive immunoassay, determination of a functional assay is

5 recommended if possible. Depending on the individual setting, a functional assay will be

6 conducted in more cases as well.

7 There are nevertheless other ways of combining different diagnostic tests as well and all have the

8 potential of reducing the number of false-positive and false-negative classifications. For

9 example, a clinical scoring system and an immunoassay can be determined in parallel as

10 suggested by several authors $(2,34,104)$, and probabilities of clinical scoring systems and-

11 immuneassays-can be combined with the use of likelihood ratios and Bayes' theorem (24, 104,

12 105). However, prospective studies evaluating these tools are still needed.

\section{Conclusion}

HIT is a life-threatening situation that requires an immediate diagnostic work-up. Not only missing a patient with HIT can result in catastrophic consequences, but overtreatment also carries a significant risk. The diagnostic work-up is, however, difficult due to a number of practical issues and limitations in the diagnostic accuracy of available assays. The diagnostic pathway should be adjusted to the individual setting using well-defined diagnostic algorithms. The first step should include the assessment of the clinical probability according to a validated scoring system and laboratory investigations should additionally be performed if the probability is intermediate or high. An immunoassay with adequate sensitivity and specificity should be used to avoid over-treatment or failure to recognise HIT. Future efforts to address these challenges should focus on the improvement and clinical evaluation of diagnostic algorithms. 


\section{1}

\section{Conflict of Interest}

MN has received research grants or lecture fees from Bayer and CSL Behring.

\section{Acknowledgment:}

The authors thank Professor Andreas Greinacher and Professor Theodore Warkentin for helpful discussion. T.B. was supported by a grant from the German Research Foundation (DFG; BA5158-1).

\section{References}

1. Bakchoul T. Current insight in the laboratory diagnosis of hit. International journal of laboratory hematology 2014; 36: 16.

2. Cuker A. Clinical and laboratory diagnosis of heparin-induced thrombocytopenia: an integrated approach. Seminars in thrombosis and hemostasis 2014; 40(1): 106-14.

3. Warkentin TE, Greinacher A, Gruel Y, et al. Laboratory testing for heparin-induced thrombocytopenia: a conceptual framework and implications for diagnosis. Journal of thrombosis and haemostasis : JTH 2011; 9(12): 2498-500.

4. Otis SA, Zehnder JL. Heparin-induced thrombocytopenia: current status and diagnostic challenges. American journal of hematology 2010; 85(9): 700-6.

5. Cuker A, Cines DB. How I treat heparin-induced thrombocytopenia. Blood 2012; 119(10): 2209-18.

6. Price EA, Hayward CP, Moffat KA, et al. Laboratory testing for heparin-induced thrombocytopenia is inconsistent in North America: a survey of North American specialized coagulation laboratories. Thrombosis and haemostasis 2007; 98(6): 1357-61.

7. Greinacher A. Heparin-induced thrombocytopenia. Journal of thrombosis and haemostasis : JTH 2009; 7 Suppl 1: 9-12.

8. Greinacher A. CLINICAL PRACTICE. Heparin-Induced Thrombocytopenia. The New England journal of medicine 2015; 373(3): 252-61.

9. Linkins LA, Dans AL, Moores LK, et al. Treatment and prevention of heparin-induced thrombocytopenia: Antithrombotic Therapy and Prevention of Thrombosis, 9th ed: American College of Chest Physicians Evidence-Based Clinical Practice Guidelines. Chest 2012; 141(2 Suppl): e495S-530S.

10. Warkentin TE. How I diagnose and manage HIT. Hematology / the Education Program of the American Society of Hematology American Society of Hematology Education Program 2011; 2011: 143-9.

11. Warkentin TE, Kelton JG. A 14-year study of heparin-induced thrombocytopenia. The American journal of medicine 1996; 101(5): 502-7. 
12. Tardy B, Lecompte T, Boelhen F, et al. Predictive factors for thrombosis and major bleeding in an observational study in 181 patients with heparin-induced thrombocytopenia treated with lepirudin. Blood 2006; 108(5): 1492-6.

13. Greinacher A, Lubenow N, Eichler P. Anaphylactic and anaphylactoid reactions associated with lepirudin in patients with heparin-induced thrombocytopenia. Circulation 2003; 108(17): 2062-5.

14. Cuker A. Heparin-induced thrombocytopenia (HIT) in 2011: an epidemic of overdiagnosis. Thrombosis and haemostasis 2011; 106(6): 993-4.

15. Warkentin TE, Linkins LA. Immunoassays are not created equal. Journal of thrombosis and haemostasis : JTH 2009; 7(8): 1256-9.

16. Alatri A, Armstrong AE, Greinacher A, et al. Results of a consensus meeting on the use of argatroban in patients with heparin-induced thrombocytopenia requiring antithrombotic therapy - a European Perspective. Thrombosis research 2012; 129(4): 426-33.

17. Watson H, Davidson S, Keeling D, et al. Guidelines on the diagnosis and management of heparin-induced thrombocytopenia: second edition. British journal of haematology 2012; 159(5): 528-40.

18. Lo GK, Juhl D, Warkentin TE, et al. Evaluation of pretest clinical score (4 T's) for the diagnosis of heparin-induced thrombocytopenia in two clinical settings. Journal of Thrombosis and Haemostasis 2006; 4(4): 759-65.

19. Cuker A, Gimotty PA, Crowther MA, et al. Predictive value of the 4Ts scoring system for heparin-induced thrombocytopenia: a systematic review and meta-analysis. Blood 2012; 120(20): 4160-7.

20. Lillo-Le Louet A, Boutouyrie P, Alhenc-Gelas M, et al. Diagnostic score for heparininduced thrombocytopenia after cardiopulmonary bypass. Journal of thrombosis and haemostasis : JTH 2004; 2(11): 1882-8.

21. Pouplard C, Gueret P, Fouassier M, et al. Prospective evaluation of the '4Ts' score and particle gel immunoassay specific to heparin/PF4 for the diagnosis of heparin-induced thrombocytopenia. Journal of thrombosis and haemostasis : JTH 2007; 5(7): 1373-9.

22. Bryant A, Low J, Austin S, et al. Timely diagnosis and management of heparin-induced thrombocytopenia in a frequent request, low incidence single centre using clinical 4T's score and particle gel immunoassay. British journal of haematology 2008; 143(5): 721-6.

23. Bakchoul T, Giptner A, Najaoui A, et al. Prospective evaluation of PF4/heparin immunoassays for the diagnosis of heparin-induced thrombocytopenia. Journal of thrombosis and haemostasis : JTH 2009; 7(8): 1260-5.

24. Nellen V, Sulzer I, Barizzi G, et al. Rapid exclusion or confirmation of heparin-induced thrombocytopenia: A single-center experience with 1,291 patients. Haematologica 2012; 97(1): 89-97.

25. Tawfik NM, Hegazy MA, Hassan EA, et al. Egyptian experience of reliability of 4T's score in diagnosis of heparin induced thrombocytopenia syndrome. Blood Coagulation and Fibrinolysis 2011; 22(8): 701-5.

26. Denys B, Stove V, Philippe J, et al. A clinical-laboratory approach contributing to a rapid and reliable diagnosis of heparin-induced thrombocytopenia. Thrombosis research 2008; 123(1): 137-45. 
27. Crowther MA, Cook DJ, Albert M, et al. The 4Ts scoring system for heparin-induced thrombocytopenia in medical-surgical intensive care unit patients. Journal of critical care 2010; 25(2): 287-93.

28. Berry C, Tcherniantchouk O, Ley EJ, et al. Overdiagnosis of heparin-induced thrombocytopenia in surgical ICU patients. Journal of the American College of Surgeons 2011; 213(1): 10-7.

29. Cuker A, Arepally G, Crowther MA, et al. The HIT Expert Probability (HEP) Score: A novel pre-test probability model for heparin-induced thrombocytopenia based on broad expert opinion. Journal of Thrombosis and Haemostasis 2010; 8(12): 2642-50.

30. Demma LJ, Winkler AM, Levy JH. A diagnosis of heparin-induced thrombocytopenia with combined clinical and laboratory methods in cardiothoracic surgical intensive care unit patients. Anesthesia and analgesia 2011; 113(4): 697-702.

31. Nagler M, Fabbro T, Wuillemin WA. Prospective evaluation of the interobserver reliability of the $4 \mathrm{Ts}$ score in patients with suspected heparin-induced thrombocytopenia. Journal of thrombosis and haemostasis : JTH 2012; 10(1): 151-2.

32. Nagler M, Angelillo-Scherrer A. Diagnostic value of the 4Ts score for heparin-induced thrombocytopenia in the critically ill. Journal of critical care 2014; 29(6): 1126-7.

33. Linkins LA, Bates SM, Lee AY, et al. Combination of 4Ts score and PF4/H-PaGIA for diagnosis and management of heparin-induced thrombocytopenia: prospective cohort study. Blood 2015; 126(5): 597-603.

34. Favaloro EJ. Toward improved diagnosis of HIT. Blood 2015; 126(5): 563-4.

35. Messmore HL, Fabbrini N, Bird ML, et al. Simple scoring system for early management of heparin-induced thrombocytopenia. Clinical and Applied Thrombosis/Hemostasis 2011; 17(2): 197-201.

36. Piednoir P, Allou N, Provenchere S, et al. Heparin-induced thrombocytopenia after cardiac surgery: an observational study of 1,722 patients. Journal of cardiothoracic and vascular anesthesia 2012; 26(4): 585-90.

37. Amiral J, Bridey F, Dreyfus M, et al. Platelet factor 4 complexed to heparin is the target for antibodies generated in heparin-induced thrombocytopenia. Thrombosis and haemostasis 1992; 68(1): 95-6.

38. Greinacher A, Amiral J, Dummel V, et al. Laboratory diagnosis of heparin-associated thrombocytopenia and comparison of platelet aggregation test, heparin-induced platelet activation test, and platelet factor 4/heparin enzyme-linked immunosorbent assay. Transfusion 1994; 34(5): 381-5.

39. Arepally G, Reynolds C, Tomaski A, et al. Comparison of PF4/heparin ELISA assay with the 14C-serotonin release assay in the diagnosis of heparin-induced thrombocytopenia. American journal of clinical pathology 1995; 104(6): 648-54.

40. Shelat SG, Tomaski A, Pollak ES. Serologic results in $>1000$ patients with suspected heparin-induced thrombocytopenia. Clinical and applied thrombosis/hemostasis : official journal of the International Academy of Clinical and Applied Thrombosis/Hemostasis 2008; 14(4): 4104. 
41. Morel-Kopp MC, Aboud M, Tan CW, et al. Heparin-induced thrombocytopenia: Evaluation of IgG and IgGAM ELISA assays. International journal of laboratory hematology 2011; 33(3): 245-50.

42. Greinacher A, Juhl D, Strobel U, et al. Heparin-induced thrombocytopenia: A prospective study on the incidence, platelet-activating capacity and clinical significance of antiplatelet factor 4/heparin antibodies of the IgG, IgM, and IgA classes. Journal of thrombosis and haemostasis : JTH 2007; 5(8): 1666-73.

43. Warkentin TE, Sheppard JI, Moore JC, et al. Quantitative interpretation of optical density measurements using PF4-dependent enzyme-immunoassays. Journal of thrombosis and haemostasis : JTH 2008; 6(8): 1304-12.

44. Vitale M, Tazzari P, Ricci F, et al. Comparison between different laboratory tests for the detection and prevention of heparin-induced thrombocytopenia. Cytometry 2001; 46(5): 290-5.

45. Nasr R, Owaidah T. Validation of monospecific elisa test as a screening test for heparin indused thrombocytopenia compare to other immunological and functional assays. Journal of thrombosis and haemostasis : JTH 2011; 9: 333.

46. Schwarz N, Luxembourg B, Kroll H, et al. Performance of anti-heparin/platelet factor 4assays in the diagnosis of heparin-induced thrombocytopenia (HIT) defined by clinical criteria. Journal of Thrombosis and Haemostasis 2009; 7 (S2): 869.

47. Andrews DM, Cubillos GF, Paulino SK, et al. Prospective observational evaluation of the particle immunofiltration anti-platelet factor 4 rapid assay in MICU patients with thrombocytopenia. Critical Care 2013; 17(4).

48. Pouplard C, Leroux D, Regina S, et al. Effectiveness of a new immuno-assay for the diagnosis of heparin-induced thrombocytopenia and improved specificity when detecting $\operatorname{IgG}$ antibodies. Thrombosis and haemostasis 2010; 103(1): 145-50.

49. Juhl D, Eichler P, Lubenow N, et al. Incidence and clinical significance of anti$\mathrm{PF} 4 /$ heparin antibodies of the IgG, IgM, and IgA class in 755 consecutive patient samples referred for diagnostic testing for heparin-induced thrombocytopenia. European journal of haematology 2006; 76(5): 420-6.

50. Farahani N, Tcherniantchouk O, Kitahara S. Cost-effective HIT diagnosis: Utilizing IgGspecific PF4 assays reduces the number of confirmatory serotonin release assays without missing true HIT. Journal of thrombosis and haemostasis : JTH 2013; 11: 937.

51. Haouach K, Admou B, Lauriant P, et al. Contributions of biological tests and the 4 Ts score in the diagnosis of heparin induced thrombocytopenia. The Pan African medical journal 2012; 13.

52. Eichler P, Raschke R, Lubenow N, et al. The new ID-heparin/PF4 antibody test for rapid detection of heparin-induced antibodies in comparison with functional and antigenic assays.

British journal of haematology 2002; 116(4): 887-91.

53. Izban KF, Lietz HW, Hoppensteadt DA, et al. Comparison of two PF4/heparin ELISA assays for the laboratory diagnosis of heparin-Induced thrombocytopenia. Seminars in thrombosis and hemostasis 1999; 25(2 SUPPL. 1): 51-6.

54. Kapadia FN, Ketkar AS, Deshpande AS, et al. Evaluation of various laboratory assays in detection of heparin-induced thrombocytopenia in an adult general ICU. International journal of laboratory hematology 2013; 35(2): 137-43. 
55. Tazzari PL, Ricci F, Vitale M, et al. Heparin-induced thrombocytopenia: Detection of antiheparin/PF4 antibodies by means of heparin/PF4-coated beads and flow cytometry. Transfusion medicine (Oxford, England) 2002; 12(3): 193-8.

56. Van Hoecke F, Devreese K. Evaluation of two new automated chemiluminescent assays (HemosILAcuStar HIT-IgG and HemosILAcuStar HIT-Ab) for the detection of heparin-induced antibodies in the diagnosis of heparin-induced thrombocytopenia. International journal of laboratory hematology 2012; 34(4): 410-6.

57. Javela K, Koskinen S. Comparison of a heparin-platelet factor 4 (PF4)-ELISA IgG/M/A and the heparin-induced platelet activation assay (HIPA) with a PF4-ELISA IgG. Vox sanguinis 2010; 99: 27-8.

58. Minet V, Bailly N, Douxfils J, et al. Assessment of the performances of AcuStar HIT and the combination with heparin-induced multiple electrode aggregometry: A retrospective study. Thrombosis research 2013; 132(3): 352-9.

59. Kiefel V, Schonberner-Richter I, Lange B. Lateral flow immunoassay-a useful tool for detection of PF4/heparin antibodies in HIT? Hamostaseologie 2012; 32 (1): A83-A4.

60. Look KA, Sahud M, Flaherty S, et al. Heparin-induced platelet aggregation vs platelet factor 4 enzyme-linked immunosorbent assay in the diagnosis of heparin-induced thrombocytopenia- thrombosis. American journal of clinical pathology 1997; 108(1): 78-82.

61. Pierce W, Mazur J, Greenberg C, et al. Evaluation of heparin-induced thrombocytopenia (HIT) laboratory testing and the 4Ts scoring system in the intensive care unit. Annals of clinical and laboratory science $2013 ; 43(4)$ : 429-35.

62. Verma AK, Levine M, Shalansky SJ, et al. Frequency of heparin-induced thrombocytopenia in critical care patients. Pharmacotherapy 2003; 23(6): 745-53.

63. Shaheed G, Malkovska V, Mendoza J, et al. PF4 ENHANCED assay for the diagnosis of heparin-induced thrombocytopenia in complex medical and surgical patients. Critical care medicine 2007; 35(7): 1691-5.

64. Nagler M, Bachmann LM, Ten Cate H, et al. Diagnostic value of immunoassays for heparin-induced thrombocytopenia: a systematic review and meta-analysis. Blood 2016; 127(5): 546-57.

65. Smock KJ, Ledford-Kraemer MR, Meijer P, et al. Proficiency testing results for heparininduced thrombocytopenia in north america. Seminars in thrombosis and hemostasis 2014; 40(2): 254-60.

66. Althaus K, Strobel U, Warkentin TE, et al. Combined use of the high heparin step and optical density to optimize diagnostic sensitivity and specificity of an anti-PF4/heparin enzymeimmunoassay. Thrombosis research 2011; 128(3): 256-60.

67. Bakchoul T, Giptner A, Bein G, et al. Performance characteristics of two commercially available IgG-specific immunoassays in the assessment of heparin-induced thrombocytopenia (HIT). Thrombosis research 2011; 127(4): 345-8.

68. Denys B, Devreese K. A clinical-laboratory approach contributing to a rapid and reliable diagnosis of heparin-induced thrombocytopenia: An update. Thrombosis research 2009; 124(5): 642-3. 
69. Kolde HJ, Dostatni R, Mauracher S. Rapid and simple IgG specific test for the exclusion of heparin induced thrombocytopenia (HIT). Clinical chemistry and laboratory medicine : CCLM / FESCC 2011; 49(12): 2065-8.

70. Novelli C, Erba N, Gatti A, et al. Evaluation of a new rapid test for detection of anti PF4heparin antibodies in hit diagnosis. Blood Transfus 2012; 10: s69.

71. Sachs UJ, von Hesberg J, Santoso S, et al. Evaluation of a new nanoparticle-based lateralflow immunoassay for the exclusion of heparin-induced thrombocytopenia (HIT). Thrombosis and haemostasis 2011; 106(6): 1197-202.

72. Seidel H, Hoffmann T, Wulfing AH, et al. Laboratory and clinical performance of rapid immunoassays in diagnosis of heparin induced thrombocytopenia: Comparison of lateral flow and gel centrifugation with ELISA technique. Hamostaseologie 2013; 33 (1): A71.

73. Nagler M, Bachmann LM, Ten Cate H, et al. Diagnostic value of immunoassays for heparin-induced thrombocytopenia: a systematic review and meta-analysis. Blood 2015.

74. Alhaliq AR, Joshua D, Kershaw G, et al. The Diamed assay has a poor positive predictive value for HIT in a tertiary hospital referral setting [1]. International journal of laboratory hematology 2007; 29(1): 69-70.

75. Leroux D, Hezard N, Lebreton A, et al. Prospective evaluation of a rapid nanoparticlebased lateral flow immunoassay $(\operatorname{STic} \operatorname{Expert}((\mathrm{R}))$ HIT) for the diagnosis of heparin-induced thrombocytopenia. British journal of haematology 2014; 166(5): 774-82.

76. Kolde HJ, Habrecht U, Von Hesberg J, et al. Multicentric validation of a rapid assay for heparin-induced thrombocytopenia with different specimen types. Blood coagulation \& fibrinolysis : an international journal in haemostasis and thrombosis 2014; 25(1): 6-9.

77. Warkentin TE, Sheppard JI, Raschke R, et al. Performance characteristics of a rapid assay for anti-PF4/heparin antibodies: The particle immunofiltration assay [5]. Journal of Thrombosis and Haemostasis 2007; 5(11): 2308-10.

78. Legnani C, Cini M, Pili C, et al. Evaluation of a new automated panel of assays for the detection of anti-PF4/heparin antibodies in patients suspected of having heparin-induced thrombocytopenia. Thrombosis and haemostasis 2010; 104(2): 402-9.

79. Archambault AJ, Dolan EJ, Arkin CF. Comparison of the hemosil HIT-AB1 to the standard ELISA assay for heparin-induced thrombocytopenia (HIT) antibody. American journal of hematology 2012; 87: S184.

80. Althaus K, Hron G, Strobel U, et al. Evaluation of automated immunoassays in the diagnosis of heparin induced thrombocytopenia. Thrombosis research 2013; 131(3): e85-e90.

81. Minet V, Baudar J, Bailly N, et al. Rapid exclusion of the diagnosis of immune HIT by AcuStar HIT and heparin-induced multiple electrode aggregometry. Thrombosis research 2014; 133(6): 1074-8.

82. Sun L, Gimotty PA, Lakshmanan S, et al. Diagnostic accuracy of rapid immunoassays for heparin-induced thrombocytopenia. A systematic review and meta-analysis. Thrombosis and haemostasis 2016; 115(5).

83. Caton S, O'Brien E, Pannelay AJ, et al. Assessing the clinical and cost impact of ondemand immunoassay testing for the diagnosis of heparin induced thrombocytopenia.

Thrombosis research 2016; 140: 155-62.
Formatiert: Deutsch (Deutschland)

Formatiert: Deutsch

(Deutschland)

Formatiert: Deutsch (Deutschland) 
84. Warkentin TE. PF4-dependent immunoassays and inferential detection of HIT antibodies. Journal of Thrombosis and Haemostasis 2007; 5(2): 232-4.

85. Bakchoul T, Zollner H, Greinacher A. Current insights into the laboratory diagnosis of HIT. International journal of laboratory hematology 2014; 36(3): 296-305.

86. Warkentin TE, Sheppard JAI, Moore JC, et al. Laboratory testing for the antibodies that cause heparin-induced thrombocytopenia: How much class do we need? Journal of Laboratory and Clinical Medicine 2005; 146(6): 341-6.

87. Sheridan D, Carter C, Kelton JG. A diagnostic test for heparin-induced thrombocytopenia. Blood 1986; 67(1): 27-30.

88. Greinacher A, Michels I, Kiefel V, et al. A rapid and sensitive test for diagnosing heparin-associated thrombocytopenia. Thrombosis and haemostasis 1991; 66(6): 734-6.

89. Warkentin TE. HIT paradigms and paradoxes. Journal of thrombosis and haemostasis : JTH 2011; 9 Suppl 1: 105-17.

90. Favaloro EJ, Bernal-Hoyos E, Exner T, et al. Heparin-induced thrombocytopenia: laboratory investigation and confirmation of diagnosis. Pathology 1992; 24(3): 177-83.

Formatiert: Deutsch (Deutschland)

Formatiert: Deutsch (Deutschland)

91. Warkentin TE, Arnold DM, Nazi I, et al. The platelet serotonin-release assay. American journal of hematology 2015; 90(6): 564-72.

92. Morel-Kopp MC, Aboud M, Tan CW, et al. Whole blood impedance aggregometry detects heparin-induced thrombocytopenia antibodies. Thrombosis research 2010; 125(5): e234e9.

93. Stricker H, Lammle B, Furlan M, et al. Heparin-dependent in vitro aggregation of normal platelets by plasma of a patient with heparin-induced skin necrosis: specific diagnostic test for a rare side effect. The American journal of medicine 1988; 85(5): 721-4.

94. Chong BH, Burgess J, Ismail F. The clinical usefulness of the platelet aggregation test for the diagnosis of heparin-induced thrombocytopenia. Thrombosis and haemostasis 1993; 69(4): $344-50$.

95. Tomer A, Masalunga C, Abshire TC. Determination of heparin-induced thrombocytopenia: A rapid flow cytometric assay for direct demonstration of antibody-mediated platelet activation. American journal of hematology 1999; 61(1): 53-61.

96. Gobbi G, Mirandola P, Tazzari PL, et al. New Laboratory Test in Flow Cytometry for the Combined Analysis of Serologic and Cellular Parameters in the Diagnosis of Heparin-Induced Thrombocytopenia. Cytometry Part B - Clinical Cytometry 2004; 58(1): 32-8.

97. Lee DH, Warkentin TE, Denomme GA, et al. A diagnostic test for heparin-induced thrombocytopenia: Detection of platelet microparticles using flow cytometry. British journal of haematology 1996; 95(4): 724-31.

98. Mullier F, Bailly N, Cornet Y, et al. Contribution of platelet microparticles generation assay to the diagnosis of type II heparin-induced thrombocytopenia. Thrombosis and haemostasis 2010; 103(6): 1277-81.

99. Greinacher A, Ittermann T, Bagemuhl J, et al. Heparin-induced thrombocytopenia: towards standardization of platelet factor $4 /$ heparin antigen tests. Journal of thrombosis and haemostasis : JTH 2010; 8(9): 2025-31. 
100. Lindhoff-Last E, Gerdsen F, Ackermann H, et al. Determination of heparin-platelet factor 4-IgG antibodies improves diagnosis of heparin-induced thrombocytopenia. British journal of haematology 2001; 113(4): 886-90.

101. Warkentin TE, Sheppard JI. No significant improvement in diagnostic specificity of an anti-PF4/ polyanion immunoassay with use of high heparin confirmatory procedure [10]. Journal of Thrombosis and Haemostasis 2006; 4(1): 281-2.

102. McGowan KE, Makari J, Diamantouros A, et al. Reducing the hospital burden of heparin-induced thrombocytopenia: impact of an avoid-heparin program. Blood 2016; 127(16): 1954-9.

103. Wallis DE, Workman DL, Lewis BE, et al. Failure of early heparin cessation as treatment for heparin-induced thrombocytopenia. The American journal of medicine 1999; 106(6): 629-35.

104. Cuker A. Does my patient have HIT? There should be an app for that. Blood 2016; 127(5): 522-4.

105. Raschke RA, Curry SC, Warkentin TE, et al. Improving clinical interpretation of the antiplatelet factor 4/heparin enzyme-linked immunosorbent assay for the diagnosis of heparininduced thrombocytopenia through the use of receiver operating characteristic analysis, stratumspecific likelihood ratios, and Bayes theorem. Chest 2013; 144(4): 1269-75.

106. Morel-Kopp MC, Tan CW, Brighton TA, et al. Validation of whole blood impedance aggregometry as a new diagnostic tool for HIT: results of a large Australian study. Thrombosis and haemostasis 2012; 107(3): 575-83. 


\section{Tables}

Table 1: Available immunoassays for the diagnosis of HIT (adapted from (73))

\begin{tabular}{|c|c|c|c|c|}
\hline Type of assay & $\begin{array}{l}\text { Available antibody } \\
\text { specificities }\end{array}$ & $\begin{array}{l}\text { Measurement } \\
\text { scale }\end{array}$ & Practical issues & Manufacturers \\
\hline \multirow{5}{*}{$\begin{array}{l}\text { Enzyme-linked } \\
\text { immunosorbent assay } \\
\text { (ELISA) }\end{array}$} & \multirow{5}{*}{$\begin{array}{l}\text { Polyspecific } \\
\text { lgG specific }\end{array}$} & Optical density & \multirow{5}{*}{$\begin{array}{l}\text { Requires specialised } \\
\text { laboratory, determination in } \\
\text { batches, daily determination } \\
\text { rarely possible }\end{array}$} & $\begin{array}{l}\text { Genetic testing institute [GTI] Diagnostics, Waukesha, WI, USA (GTI- } \\
\text { PF4; HAT; PF4-Enhanced; GTI-IgG) }\end{array}$ \\
\hline & & \multirow[t]{4}{*}{$\begin{array}{l}\text { Low, intermediate } \\
\text { and high threshold* }\end{array}$} & & $\begin{array}{l}\text { Hyphen-BioMed, Neuville-Sur-Oise, France (Zymutest HIA IgGAM; } \\
\text { Zymutest HIA IgG) }\end{array}$ \\
\hline & & & & Diagnostica Stago, Asnières-sur-Seine, France (Asserachrom HPIA) \\
\hline & & & & Gen-Probe-Waukesha, Waukesha, WI, USA (Gen-Probe PF4) ${ }^{\#}$ \\
\hline & & & & Technoclone GmbH, Vienna, Austria (Technozym) \\
\hline \multirow[t]{2}{*}{$\begin{array}{l}\text { Particle gel } \\
\text { immunoassay (PaGIA) }\end{array}$} & \multirow[t]{2}{*}{ Polyspecific } & $\begin{array}{l}\text { Visual assessment } \\
\text { of agglutination }\end{array}$ & \multirow{2}{*}{$\begin{array}{l}\text { Determination in standard } \\
\text { laboratories possible, } 24 \text {-hour } \\
\text { service, observer-dependent }\end{array}$} & \multirow[t]{2}{*}{ Diamed, Cressier sur Morat, Switzerland (ID-H/PF4 PaGIA) } \\
\hline & & 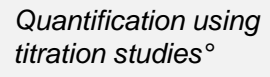 & & \\
\hline $\begin{array}{l}\text { Particle immunofiltration } \\
\text { assay }\end{array}$ & Polyspecific & Visual assessment & Observer-dependent & Akers Biosciences Inc, Thorofare, NJ, USA (HealthTEST) \\
\hline \multirow{2}{*}{$\begin{array}{l}\text { Lateral flow } \\
\text { immunoassay }\end{array}$} & \multirow[t]{2}{*}{ IgG specific } & \multirow{2}{*}{$\begin{array}{l}\text { Visual or automated } \\
\text { assessment }^{\circ}\end{array}$} & \multirow{2}{*}{$\begin{array}{l}\text { Determination in standard } \\
\text { laboratories possible, } 24 \text {-hour } \\
\text { service }\end{array}$} & Diagnostica Stago, Asnières-sur-Seine, France (STic EXPERT HIT) \\
\hline & & & & Milenia Biotec, Giessen, Germany (Milenia QuickLine HIT) \\
\hline \multirow[t]{2}{*}{$\begin{array}{l}\text { Chemiluminescent } \\
\text { immunoassay(CLIA) }\end{array}$} & \multirow{2}{*}{$\begin{array}{l}\text { Polyspecific } \\
\text { IgG specific }\end{array}$} & \multirow{2}{*}{$\begin{array}{l}\text { Detection of emitted } \\
\text { light } \\
\text { Low, intermediate } \\
\text { and high thresholdt }\end{array}$} & \multirow{2}{*}{$\begin{array}{l}\text { Automated determination } \\
\text { possible, 24-hour service, } \\
\text { expensive }\end{array}$} & \multirow{2}{*}{$\begin{array}{l}\text { Instrumentation Laboratory, Bedford, MA, USA (HemosIL AcuStar HIT- } \\
\text { Ab; HemosIL AcuStar HIT-lgG) }\end{array}$} \\
\hline & & & & \\
\hline $\begin{array}{l}\text { Latex agglutination } \\
\text { assay }\end{array}$ & Polyspecific & $\begin{array}{l}\text { Inhibition of } \\
\text { agglutination }\end{array}$ & $\begin{array}{l}\text { Automatized determination } \\
\text { possible, } 24 \text {-hour service, } \\
\text { expensive }\end{array}$ & Instrumentation Laboratory, Bedford, MA, USA (HemosIL HIT-Ab) \\
\hline
\end{tabular}

* low threshold: below or equal to OD 0.7 , intermediate threshold: between OD 0.8 and 1.4, high threshold: above OD 1.4; ${ }^{\circ}$ positive/negative; $\dagger$ low threshold: below $1.0 \mathrm{U} / \mathrm{ml}$, intermediate threshold: between 1.0 and $2.8 \mathrm{U} / \mathrm{ml}$, high threshold: above $2.8 \mathrm{U} / \mathrm{ml} ;{ }^{*}$ technically identical with $\mathrm{GTI}$ assay 
Table 2: Diagnostic accuracy of immunoassays for diagnosis of $\mathrm{HIT}^{+}$

\begin{tabular}{|c|c|c|c|c|}
\hline \multirow[t]{2}{*}{ Type of test } & \multirow[t]{2}{*}{ Sensitivity } & \multirow{2}{*}{$\begin{array}{c}\text { Specificity } \\
\text { (percentages) }\end{array}$} & \multicolumn{2}{|c|}{ Likelihood ratio } \\
\hline & & & Positive (95\% Cl) & Negative $(95 \% \mathrm{Cl})$ \\
\hline \multicolumn{5}{|l|}{ Polyspecific ELISA } \\
\hline Low threshold ${ }^{*}$ & $96.7(89.7,99.0)$ & $86.8(82.0,90.5)$ & $7.3(5.4,10.0)$ & $0.04(0.01,0.12)$ \\
\hline Intermediate threshold* & $98.4(90.8,99.7)$ & $94.9(90.5,97.3)$ & $19.3(10.4,36.0)$ & $0.02(0.00,0.1)$ \\
\hline High threshold* & $15.0(14.5,15.5)$ & $100(99.3,100)$ & $73.4(28.2,190.9)$ & $0.3(0.2,0.5)$ \\
\hline \multicolumn{5}{|l|}{ IgG-specific ELISA } \\
\hline Low threshold ${ }^{*}$ & $98.3(95.1,99.4)$ & $85.4(78.2,90.6)$ & $6.7(4.5,10.2)$ & $0.02(0.01,0.05)$ \\
\hline Intermediate threshold* & $91.2(86.2,94.5)$ & $93.5(89.1,96.2)$ & $14.1(8.1,24.5)$ & $0.09(0.05,0.15)$ \\
\hline High threshold ${ }^{*}$ & $60.9(59.7,62.1)$ & $99.4(97.6,100)$ & $97.0(53.0,177.6)$ & $0.4(0.3,0.5)$ \\
\hline \multicolumn{5}{|l|}{ PaGIA } \\
\hline Low threshold ${ }^{\circ}$ & $96.5(89.8,98.9)$ & $93.7(83.1,97.8)$ & $15.3(5.5,42.3)$ & $0.04(0.01,0.11)$ \\
\hline Intermediate threshold ${ }^{\circ}$ & 98.9 & 95.9 & 24.1 & 0.01 \\
\hline Lateral flow immunoassay & $98.4(85.3,99.9)$ & $90.3(84.4,94.1)$ & $10.1(6.2,16.5)$ & $0.02(0.00,0.18)$ \\
\hline Particle immunofiltration assay & 0.0 & 70.1 & 2.3 & 0.5 \\
\hline Latex agglutination assay & 100.0 & 75.6 & 3.7 & 0.0 \\
\hline \multicolumn{5}{|l|}{ Polyspecific CLlchemiluminescent immunoassayA } \\
\hline Low thresholdt & $98.9(92.7,99.8)$ & $85.6(79.3,90.3)$ & $6.9(4.7,10.0)$ & $0.01(0.00,0.09)$ \\
\hline Intermediate threshold & $97.9(94.6,100.0)$ & $93.1(90.4,95.8)$ & $13.5(9.5,18.9)$ & $0.0(0.0,0.1)$ \\
\hline High thresholdt & $98.3(69.5,99.9)$ & $97.5(94.4,98.9)$ & $39.5(17.5,89.2)$ & $0.0(0.0,0.40)$ \\
\hline \multicolumn{5}{|l|}{ IgG-specific chemiluminescent immunoassayCLIA } \\
\hline Low threshold & $98.8(69.2,100.0)$ & $94.6(90.7,96.9)$ & $18.3(10.6,31.5)$ & $0.01(0.00,0.40)$ \\
\hline Intermediate threshold + & $78.6(75.9,81.2)$ & $98.7(94.6,100)$ & $42.3(20.1,88.7)$ & $0.2(0.1,0.3)$ \\
\hline High thresholdt & $74.2(71.9,76.5)$ & $99.1(95.4,100)$ & $47.8(23.2,98.7)$ & $0.2(0.1,0.4)$ \\
\hline
\end{tabular}

${ }^{+}$According to results of a recent meta-analysis (73), please note differences between individual manufacturers; ${ }^{*}$ low threshold: below or equal to OD 0.7 , intermediate threshold: between OD 0.8 and 1.4, high threshold: above OD 1.4; ${ }^{\circ}$ low threshold: positive/negative, intermediate threshold: titer 2 to 3 ; † low threshold: below 1.0 U/ml, intermediate threshold: between 1.0 and $2.8 \mathrm{U} / \mathrm{ml}$, high threshold: above $2.8 \mathrm{U} / \mathrm{ml}$

Nagler, M. et al. Laboratory tests for HIT 
Table 3: Commonly used functional assays for diagnosis of HIT

\begin{tabular}{|c|c|c|c|c|c|}
\hline Type of test & Analytic principle & Endpoint & Platelets used & Confirmation step & Validation \\
\hline $\begin{array}{l}\text { Serotonin release assay } \\
\text { (SRA) }\end{array}$ & $\begin{array}{l}\text { Stimulation of platelet } \\
\text { serotonin release by } \\
\text { patient serum in the } \\
\text { presence of heparin }\end{array}$ & Detection of change in ${ }^{14} \mathrm{C}$ & $\begin{array}{l}\text { Washed, }{ }^{14} \mathrm{C} \text {-radiolabeled } \\
\text { platelets from one selected } \\
\text { donor }\end{array}$ & $\begin{array}{c}\text { Suppression with high- } \\
\text { dose heparin and inhibition } \\
\text { using an Fc } \gamma \text { RIIA blocking } \\
\text { antibody }\end{array}$ & $\begin{array}{l}\text { High agreement with } \\
\text { clinical HIT }(86,87)\end{array}$ \\
\hline $\begin{array}{l}\text { Heparin-induced platelet } \\
\text { activation assay (HIPA) }\end{array}$ & $\begin{array}{l}\text { Detection of platelet } \\
\text { aggregation induced by } \\
\text { patient serum in the } \\
\text { presence of heparin }\end{array}$ & $\begin{array}{l}\text { Visual assessment of } \\
\text { aggregation in microtitre } \\
\text { plates }\end{array}$ & $\begin{array}{l}\text { Washed platelets from four } \\
\text { unselected donors }\end{array}$ & $\begin{array}{c}\text { Suppression with high- } \\
\text { dose heparin and inhibition } \\
\text { using an Fc } \gamma \text { RIIA blocking } \\
\text { antibody }\end{array}$ & $\begin{array}{l}\text { High agreement with } \\
\text { clinical HIT }(38,88)\end{array}$ \\
\hline $\begin{array}{l}\text { Heparin-induced platelet } \\
\text { aggregation test (PAT) }\end{array}$ & $\begin{array}{l}\text { Activation of platelets } \\
\text { (citrated PRP) in the } \\
\text { presence of patient plasma } \\
\text { and heparin }\end{array}$ & $\begin{array}{l}\text { Detection of aggregation } \\
\text { by aggregometry }\end{array}$ & $\begin{array}{l}\text { PRP of one to four, } \\
\text { selected or unselected } \\
\text { donors }\end{array}$ & $\begin{array}{l}\text { Suppression with high- } \\
\text { dose heparin }\end{array}$ & $\begin{array}{l}\text { Varying agreement with } \\
\text { SRA, depending on } \\
\text { platelet donor (94), lower } \\
\text { sensitivity than SRA/HIPA } \\
\text { with clinical criteria }(38,90 \text {, } \\
93)\end{array}$ \\
\hline Flow cytometry & $\begin{array}{l}\text { Detection of markers for } \\
\text { platelet activation (eg. } \\
\text { CD45/GPIlb; platelet } \\
\text { microparticles; CD62; } \\
\text { annexin V) }\end{array}$ & $\begin{array}{l}\text { Increase of platelet } \\
\text { activation markers of } \\
\text { donor platelets in presence } \\
\text { of heparin }\end{array}$ & PRP of unselected donors & None & $\begin{array}{c}\text { Some agreement with } \\
\text { SRA (44, 95-98), requires } \\
\text { standardisation and further } \\
\text { evaluation }\end{array}$ \\
\hline $\begin{array}{l}\text { Whole blood impedance } \\
\text { aggregometry } \\
\text { (Multiplate®) }\end{array}$ & $\begin{array}{l}\text { Activation of whole blood } \\
\text { platelets in the presence of } \\
\text { patient plasma and } \\
\text { heparin }\end{array}$ & Changes in impedance & $\begin{array}{l}\text { Whole blood from one } \\
\text { selected donor }\end{array}$ & $\begin{array}{l}\text { Suppression with high- } \\
\text { dose heparin }\end{array}$ & $\begin{array}{l}\text { Adequate agreement with } \\
\text { SRA in two studies ( } 81 \text {, } \\
\text { 106), requires confirmation }\end{array}$ \\
\hline
\end{tabular}




\section{Figure legends}

Figure 1: Suggested diagnostic algorithm for diagnosis of HIT (adapted from (8)). The algorithm must pe adapted according to the individual setting, taking the availability of laboratory tests such as functional assays into account. Of note, using this algorithm some HIT patients with a low risk 4Ts scoring will be missed, particularly in cases with inadequately determination of the 4Ts score. Thus, several authors suggested conducting an immunoassays in all patients with suspected HIT $(24,33,34)$. However, this approach need\$ careful interpretation of immunoassay test results to avoid over-treatment.

Figure 2: Diagnostic challenges in clinical practice. The 35-year-old female patient was admitted to hospital

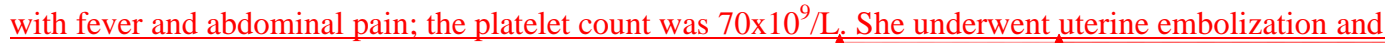
curettage 10 days earlier because of vaginal bleeding due to ectopic cervical pregnancy. HIT was rejected because of a low risk 4Ts scoring (3/8 points) and no immunoassay test was conducted (in accordance with recent guidelines). Patient suffered extensive intracranial haemorrhage three days later and cerebral venous thrombosis as well as HIT was diagnosed. Despite immediate start with lepirudin and intensive medical support, patient died on day 33.

_Figure 13: Probability of having HIT with a particular immunoassay test result according to pre-test probability. The probability of having HIT is represented by the post-test probability on the Y-axis, the clinical probability (as measured by a clinical assessment tool) is illustrated by the pre-test probability on the X-axis. Two different immunoassays are shown with curves illustrative of the probability of HIT with a positive and negative immunoassay results as indicated. It is obvious that the probability of having HIT remains low in patients with a low clinical probability despite a positive immunoassay test result. In contrast, the probability of HIT is increasing in patients with a high clinical probability, even with a negative immunoassay test result (applies mainly to assays with a limited sensitivity).

Figure 2: Suggested diagnostic algorithm for diagnosis of HHT (adapted from (8)). The algorithm must peadapted according to the individual setting, taking the availability of laboratory tests such as functional ass lys inte account. $(24,33,34)$ 